\title{
Chemical Abrasion Applied to LA-ICP-MS U-Pb Zircon Geochronology
}

\author{
Quentin G. Crowley $^{1, *}$, Kyle Heron ${ }^{1}$, Nancy Riggs ${ }^{2}$, Balz Kamber ${ }^{1}$, David Chew ${ }^{1}$, \\ Brian McConnell ${ }^{3}$ and Keith Benn ${ }^{4}$
}

1 Department of Geology, School of Natural Sciences, Trinity College, Dublin 2, Ireland; E-Mails: heronky@tcd.ie (K.H.); kamberbs@tcd.ie (B.K.); chewd@tcd.ie (D.C.)

2 School of Earth Sciences and Environmental Sustainability, Northern Arizona University, Flagstaff, AZ 86011, USA; E-Mail: nancy.riggs@nau.edu

3 Geological Survey of Ireland, Beggars Bush, Dublin 4, Ireland; E-Mail: brian.mcconnell@gsi.ie

4 Tasiast Mauritanie Limited SA, ZRA 741, BP 5051, Nouakchott, Mauritania, West Africa; E-Mail: keith.benn@kinross.com

* Author to whom correspondence should be addressed; E-Mail: crowleyq@tcd.ie; Tel.: +353-1-896-2403; Fax: +353-1-671-1199.

Received: 30 April 2014; in revised form: 19 May 2014 / Accepted: 23 May 2014 /

Published: 3 June 2014

\begin{abstract}
Zircon $\left(\mathrm{ZrSiO}_{4}\right)$ is the most commonly used mineral in $\mathrm{U}-\mathrm{Pb}$ geochronology. Although it has proven to be a robust chronometer, it can suffer from $\mathrm{Pb}$-loss or elevated common $\mathrm{Pb}$, both of which impede precision and accuracy of age determinations. Chemical abrasion of zircon involves thermal annealing followed by relatively low temperature partial dissolution in HF acid. It was specifically developed to minimize or eliminate the effects of Pb-loss prior to analysis using Thermal Ionization Mass Spectrometry (TIMS). Here we test the application of chemical abrasion to Laser Ablation Inductively Coupled Plasma Mass Spectrometry (LA-ICP-MS) by analyzing zircons from both untreated and chemically abraded samples. Rates of ablation for high alpha-dose non-treated zircons are up to $25 \%$ faster than chemically abraded equivalents. Ablation of 91500 zircon reference material demonstrates a $c a .3 \%$ greater down-hole fractionation of ${ }^{206} \mathrm{~Pb} /{ }^{238} \mathrm{U}$ for non-treated zircons. These disparities necessitate using chemical abrasion for both primary reference material and unknowns to avoid applying an incorrect laser induced fractionation correction. All treated samples display a marked increase in the degree of concordance and/or lowering of common $\mathrm{Pb}$, thereby illustrating the effectiveness of chemical abrasion to LA-ICP-MS U-Pb zircon geochronology.
\end{abstract}


Keywords: U-Pb geochronology; zircon; chemical abrasion; Laser Ablation Inductively Coupled Plasma Mass Spectrometry (LA-ICP-MS); Pb-loss

\section{Introduction}

$\mathrm{U}-\mathrm{Pb}$ geochronology is a widely used radiometric dating tool applied to geological time-scales from 800 thousand years to $>4$ billion years. This is made possible due to dual uranium parent isotopes of ${ }^{235} \mathrm{U}$ and ${ }^{238} \mathrm{U}$ decaying to ${ }^{207} \mathrm{~Pb}$ and ${ }^{206} \mathrm{~Pb}$ with half-lives of $c a .704$ million years and $c a .4 .468$ billion years respectively. $\mathrm{U}-\mathrm{Pb}$ geochronology was initially developed in the mid-1950s [1-3] and only made possible by earlier advances in mass spectrometry [4]. Thermal Ionization Mass Spectrometry (TIMS) is the method of choice for studies requiring the highest precision $\mathrm{U}-\mathrm{Pb}$ data. Micro-beam techniques such as Secondary Ionization Mass Spectrometry (SIMS) and Laser Ablation Inductively Coupled Plasma Ionization Mass Spectrometry (LA-ICP-MS) are generally used when there is a requirement for a greater number of analyses at a lower analytical precision, or where a spatially resolved analysis is beneficial. Zircon $\left(\mathrm{ZrSiO}_{4}\right)$ is the most commonly used mineral in $\mathrm{U}-\mathrm{Pb}$ geochronology and is found in a wide compositional range of igneous, metamorphic and sedimentary rocks. In terms of crystal structure and composition, zircon has a tetrahedral Si site and a distorted octahedral Zr site [5]. Hf, U, $\mathrm{Th}, \mathrm{Ti}$, rare earth elements, $\mathrm{Y}$ and $\mathrm{Sc}$ may enter the $\mathrm{Zr}$ site, but only relatively small amounts of $\mathrm{Pb}$ are accepted. As a result of this, $\mathrm{U}$ is compatible but $\mathrm{Pb}$ is incompatible in the zircon crystal structure, so that common (or initial) $\mathrm{Pb}$ is preferentially excluded at the time of zircon formation, whereas ${ }^{206} \mathrm{~Pb}$ and ${ }^{207} \mathrm{~Pb}$ can reside within zircon following in-situ radioactive decay from the parent $\mathrm{U}$ isotopes. The exact mode of incorporation and place of residence of radiogenic $\mathrm{Pb}$ in the zircon crystal structure is thought to be strongly dependent on composition, such as the presence or absence of phosphate or hydrous phases [6].

Zircon commonly occurs as an accessory phase following high-grade metamorphism and partial melting and demonstrates a high closure temperature for $\mathrm{Pb}\left(>900{ }^{\circ} \mathrm{C}[7,8]\right)$, yet paradoxically the $\mathrm{U}-\mathrm{Pb}$ isotope system may be disturbed at low temperatures resulting in $\mathrm{Pb}$-loss. Conditions resulting in zircon being susceptible to Pb-loss may arise from the crystal lattice being damaged by the emission of alpha particles and alpha recoil processes [9]. In this manner, high-U zircons or high-U domains within zircons may accumulate radiation damage and be susceptible to Pb-loss. This effect is particularly pronounced at low temperatures where there is insufficient thermal energy to repair (anneal) radiation damage to the crystal lattice. The seemingly contradictory behavior of $\mathrm{Pb}$ in zircon may be explained by a general difference in valence states for ${ }^{204} \mathrm{~Pb}$, compared to ${ }^{206} \mathrm{~Pb}$ and ${ }^{207} \mathrm{~Pb}$; although uncertainty exists, it is possible that ${ }^{204} \mathrm{~Pb}$ is divalent, whereas ${ }^{206} \mathrm{~Pb}$ and ${ }^{207} \mathrm{~Pb}$ may originally exist in tetravalent states at the site of production in the zircon crystal lattice [10,11]. Prevalence of tetravalent $\mathrm{Pb}$ in zircon may be enhanced by a strong oxidizing environment at alpha-recoil sites and would be maintained by the continuous loss of beta-particles [12]. Radiogenic $\mathrm{Pb}$ however, may subsequently be reduced during alteration processes, so divalent lead which previously existed in tetravalent form in the zircon crystal lattice may have a tendency to occupy sites affected by both accumulated radiation damage and alteration. Common $\mathrm{Pb}$ is incorporated into the zircon crystal lattice 
in small amounts, or present in micro-inclusions. Considering that divalent $\mathrm{Pb}$ is incompatible in zircon, any fluid-induced reduction of $\mathrm{Pb}^{4+}$ to $\mathrm{Pb}^{2+}$ may result in loss of $\mathrm{Pb}$. Aside from $\mathrm{Pb}$-loss being related to radiation damage, it can also arise following physical distortion of the crystal lattice structure during rock deformation processes (e.g., shearing). This phenomenon results in mobilization of $\mathrm{Pb}$ from distorted zircons and can occur at lower metamorphic grade than in undistorted counterparts [13]. The $\mathrm{U}-\mathrm{Pb}$ isotope system in zircon may therefore be disturbed by a process of $\mathrm{Pb}$-loss causing erroneous younger apparent ages.

Although it is possible to obtain meaningful radiometric ages from zircons that have suffered $\mathrm{Pb}$-loss, a greater number of analyses are usually required to construct a statistically valid Discordia array and intercept ages. Additionally, these intercept ages are generally less precise than ages (e.g., a Concordia age or weighted mean ${ }^{206} \mathrm{~Pb} /{ }^{238} \mathrm{U}$ age) calculated from a uniform population of zircons with no Pb-loss. In order to reduce uncertainties due to Pb-loss a method of "air-abrasion" was developed to physically abrade the exterior portions of zircons [14]. As the outer portions of zircons are more susceptible to $\mathrm{Pb}$-loss due to either higher-U domains, and/or contact with alteration fluids, removal of these outer domains results in less discordant or concordant zircon analyses when compared with non-abraded samples. The amount of zircon removed during air-abrasion is primarily dependent on the duration of treatment, with more zircon being removed for longer abrasion periods. It is not suited to all grain morphologies (e.g., delicate acicular needles) and runs the risk of removing narrow rims which may be of a different age compared to the bulk of the zircon grain. The air abrasion method was widely adopted for over two decades as a zircon pretreatment for TIMS, where whole grains, or multi-grain fractions are subsequently dissolved and purified prior to $\mathrm{U}-\mathrm{Pb}$ isotope analysis. Although air-abrasion is still used for combating the effects of Pb-loss in minerals other than zircon (e.g., titanite), it has largely been replaced by a newly developed technique termed chemical abrasion [15]. The chemical abrasion protocol was perfected following a series of similar, but less successful attempts [16-20], to chemically pre-treat zircons and lessen, or remove, the effects of $\mathrm{Pb}$-loss. Chemical abrasion of zircon involves two steps: (1) thermally annealing grains between 850 and $1000{ }^{\circ} \mathrm{C}$ for $48 \mathrm{~h}$; and (2) subjecting annealed grains to HF acid attack for $12 \mathrm{~h}$ at temperatures below which full dissolution normally takes place. This two-step process whereby alpha track damage is thermally annealed and higher-U domains are preferentially dissolved from the entire grain also has the effect of removing more soluble forms of $\mathrm{Pb}$ (i.e., $\mathrm{Pb}^{2+}$ ).

Chemical abrasion has been adapted for incrementally dissolving complex single grains to produce high-precision TIMS ages not discernible using micro-beam techniques [21]. It has also been demonstrated to be effective for SIMS U-Pb zircon geochronology [22]. This study aims to investigate if chemical abrasion can be applied to LA-ICP-MS U-Pb zircon geochronology to reduce discordance. Although the technique has previously been applied to a small number of LA-ICP-MS U-Pb zircon studies [23-25], this particular application has not been rigorously assessed. We test a modified chemical abrasion technique by applying an annealing-leaching treatment to zircon reference materials and a range of zircons of unknown age. Comparisons of data are made between treated and un-treated zircons to assess any physical and chemical effects and to evaluate the method as a pretreatment utility prior to LA-ICP-MS analysis. 


\section{Experimental Section}

\subsection{Sample Description}

Untreated and/or chemically abraded zircons were analyzed from five samples, comprising three natural reference materials 91500 [26], Plešovice [27] and Penglai [28] and two unknowns TSUPB021 and 10/225. Non-treated Plešovice was used as a secondary reference material for non-treated samples only and is not described below.

The 91500 zircon reference material is thought to have come from a syenite pegmatite near Kuehl Lake in Ontario, Canada. The original sample consisted of a single $238 \mathrm{~g}$ crystal, part of which was split into a large number of $200 \mu \mathrm{m}$ to $2 \mathrm{~mm}$ fragments and made available to geochronology laboratories worldwide. 91500 zircon has an accepted U-Pb age of 1062.4 \pm 0.4 million years (Ma) [26]. Secondary electron (SEM) and cathodoluminesence (CL) images of a chemically abraded 91500 zircon fragment (Figure 1a) show pitting in the grain interior, resulting from etching by HF acid. Note that this pitting is not present in untreated 91500 zircon reference material [26]. All zircons were polished down to reveal grain interiors after chemical abrasion; this signifies that HF acid vapour penetrated into central portions of even large ( $c a .150 \mu \mathrm{m}$ diameter) grains.

Figure 1. Secondary electron (left) and cathodoluminesence (right) images of representative zircons from: (a) 91500-CA; (b) Penglai-CA; (c) TSUPB021; (d) TSUPB021-CA; (e) $10 / 225$; and (f) $10 / 225-C A$. Note that "-CA" indicates zircons have been subjected to chemical abrasion.
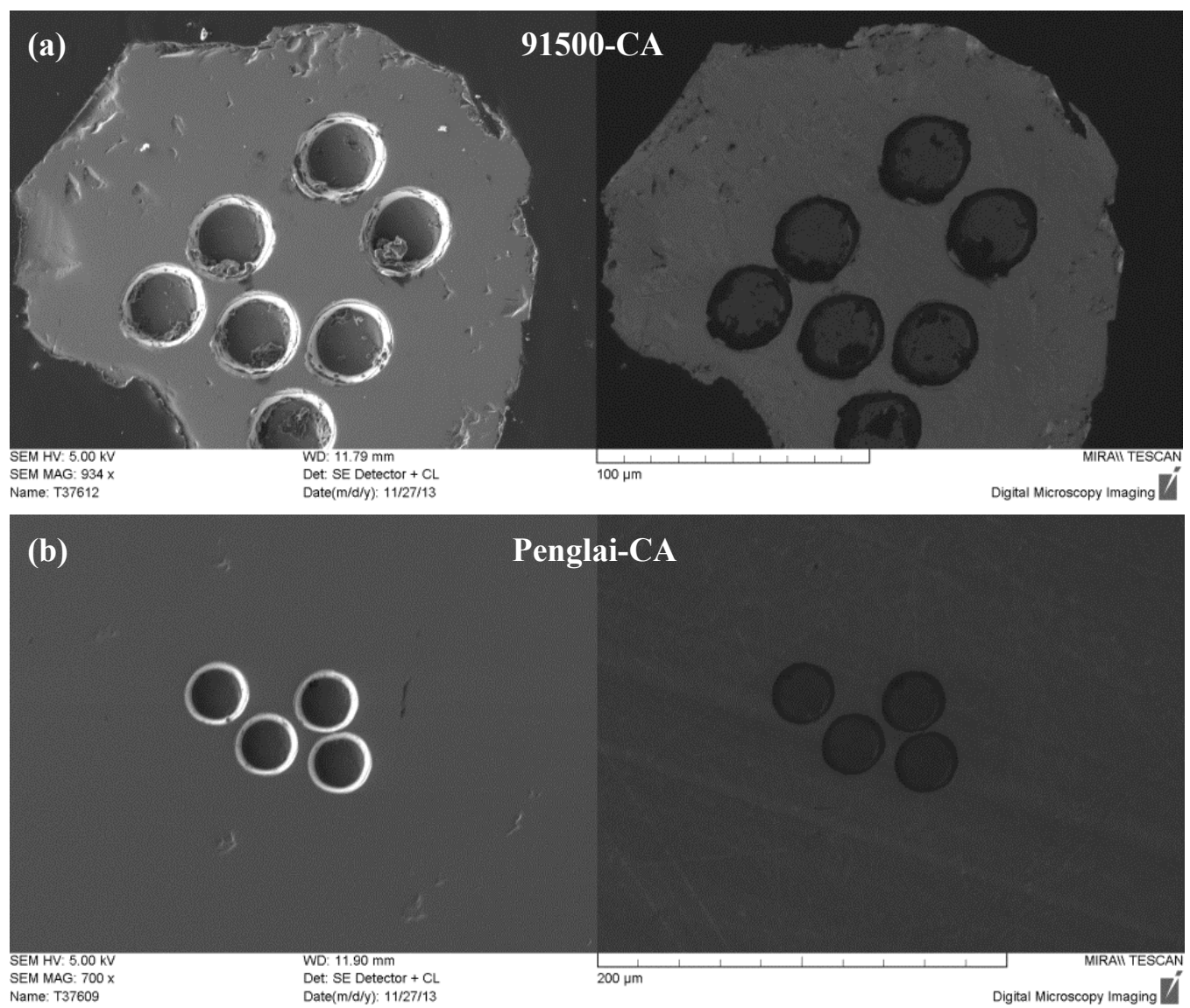
Figure 1. Cont.
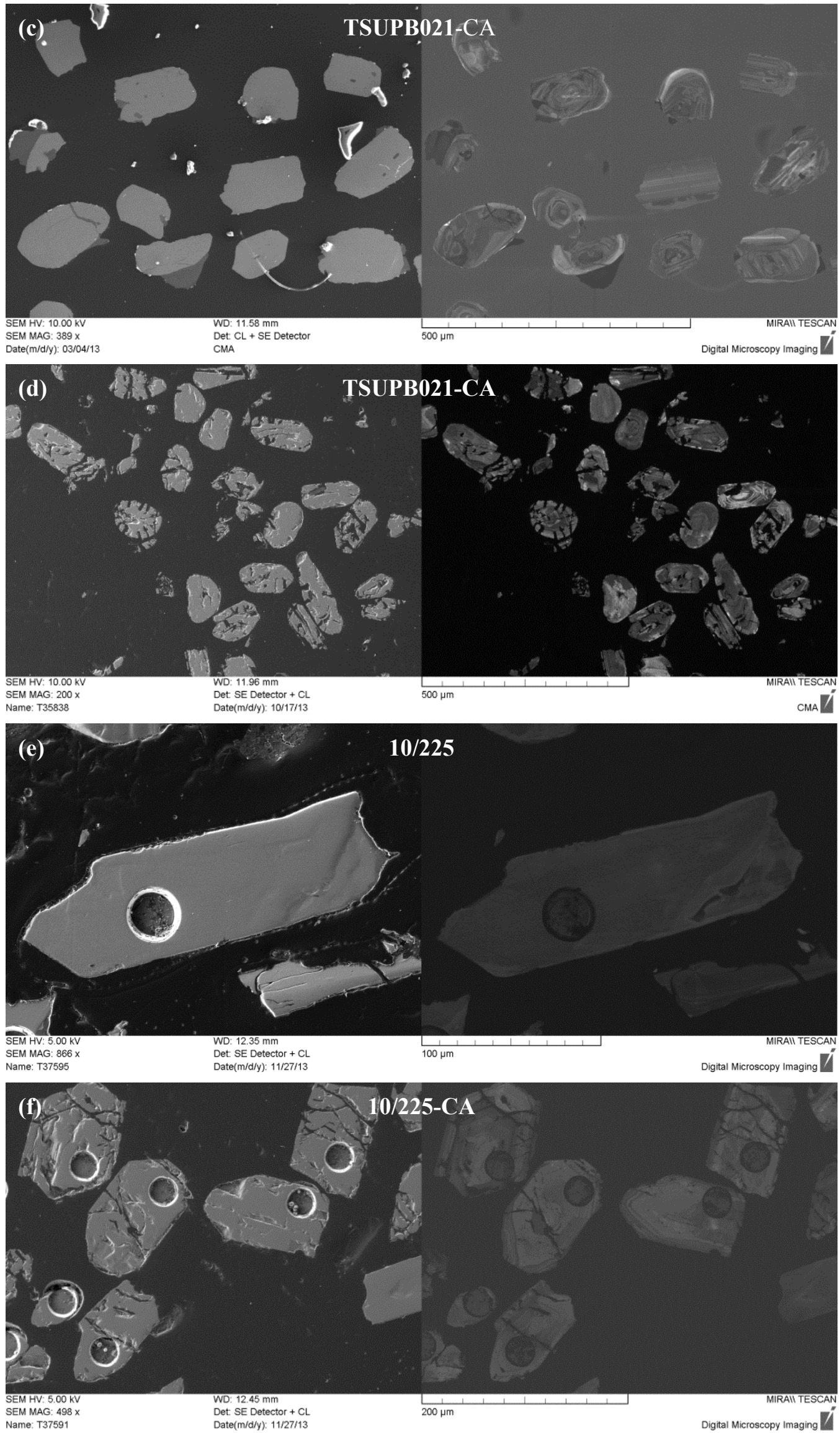
Penglai zircons are sourced from early Pliocene alkaline basalts from the northern Hainan Island of South China. Due to their abundance and large size $(>10 \mathrm{~mm})$, they were originally suggested as reference material for micro-beam analysis of $\mathrm{Hf}-\mathrm{O}$ isotopes and for $\mathrm{U}-\mathrm{Pb}$ geochronology [28]. Penglai zircons however, define a linear discordant array on a Tera-Wasserburg diagram with a "preferred" ${ }^{206} \mathrm{~Pb} /{ }^{238} \mathrm{U}$ age of $4.4 \pm 0.1 \mathrm{Ma}$ [28]. This discordance makes Penglai unsuitable for use as a primary reference material for $\mathrm{U}-\mathrm{Pb}$ geochronology, unless a common $\mathrm{Pb}$ correction is undertaken [29]. As with 91500, slight pitting due to chemical abrasion is evident in the SEM image. Oscillatory zoning is obvious in CL (Figure 1b), consistent with an igneous origin.

TSUPB021 is an Archean greywacke from the Tasiast terrane of Mauritania, West Africa. Zircons are sub-angular to rounded, $150-100 \times 100-80 \times 80-60 \mu \mathrm{m}$ and typically display oscillatory zoning in CL images (Figure 1c) indicating an igneous provenance. Metamict zircons with chaotic CL patterns are also evident, indicating that substantial radiation damage has occurred. TSUPB021 zircons subjected to chemical abrasion have been visibly and severely affected, with widespread partial dissolution along micro-cracks, radiating fractures and dark CL (high $\mathrm{U}$ ) domains throughout the grains (Figure 1d).

Sample 10/225 is a granite cobble from an Ordovician sedimentary sequence in South Mayo, west of Ireland. Zircons are euhedral to subhedral, 180-50 × 80-60 ×60-40 $\mu \mathrm{m}$ and typically display oscillatory zoning and metamict domains in CL (Figure 1e-f). Chemically abraded zircons from this sample display widespread severe pitting and dissolution zones along fractures through entire grains (Figure 1e).

\subsection{Sample Preparation}

Samples TSUPB021 and 10/225 were crushed and zircons separated by standard techniques (Rogers water table, Frantz magnetic separation, and methylene iodide heavy-liquid separation). Several hundred zircons from these samples were hand-picked under a binocular microscope, in order to ensure representative populations. Fragments of 91500 and Penglai zircon reference materials and representative zircons separated from TSUPB021 and 10/225 were thermally annealed at $850{ }^{\circ} \mathrm{C}$ in

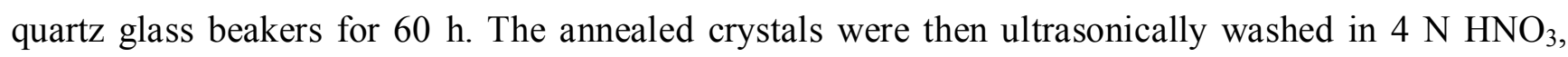
rinsed in ultra-pure water, then further washed in warm $4 \mathrm{~N} \mathrm{HNO}_{3}$ prior to rinsing with ultra-pure water to remove surface contamination. The annealed and cleaned zircon fractions were then chemically abraded in $200 \mu \mathrm{L} 29 \mathrm{~N} \mathrm{HF}$ and $20 \mu \mathrm{L} 8 \mathrm{~N} \mathrm{HNO}_{3}$ at $180{ }^{\circ} \mathrm{C}$ in modified $1.5 \mathrm{~mL}$ Teflon micro-centrifuge tubes in a Parr bomb for $12 \mathrm{~h}$. Following three separate cleaning steps in $3 \mathrm{~N} \mathrm{HCl}$ and ultra-pure water, treated and untreated zircons were mounted in separate epoxy plugs, ground down to expose grain interiors and polished with $6 \mu \mathrm{m}$ and $1 \mu \mathrm{m}$ diamond paste. All sample preparation was undertaken at the Department of Geology, Trinity College Dublin (TCD).

\subsection{Instrumentation}

Untreated zircons from sample 10/225 were analyzed at the Department of Earth Science, University of California Santa Barbara, USA (UCSB), by Multi-Collector (MC) LA-ICP-MS (Nu Plasma, Nu Instruments Ltd., Wrexham, UK) [30], whereas all others presented in this study were analyzed by Quadrupole (Q-) LA-ICP-MS (Thermo Scientific iCAP Qs, Thermo Fisher Scientific, Waltham, MA, USA) at the Department of Geology, TCD, Dublin Ireland. Both laboratories utilized a 
Photon Machines 193 nm ArF Excimer laser equipped with a HeLex ablation cell, 91500 zircon [26] as a primary reference material and Plešovice zircon [27] as a secondary reference material. A standard-sample bracketing approach was utilized using 91500 as the primary reference material after every $c a$. 10 analyses of unknowns. Chemically abraded samples were matched with chemically abraded reference materials in the same analytical session. For analyses conducted at TCD the LA-ICP-MS system was tuned while ablating a line raster on NIST SRM (National Institute of Standards, Standard Reference Material) 612 synthetic glass reference material in order to obtain optimal sensitivity for $\mathrm{Pb}$, Th and $\mathrm{U}$, while keeping $\mathrm{ThO}+/ \mathrm{Th}$ low and $\mathrm{Th} / \mathrm{U}$ close to 1 . ThO $+/ \mathrm{Th}$ and $\mathrm{Th} / \mathrm{U}$ were typically $<0.002$ and $>0.9$, respectively. Full instrument set-up conditions are given in Table 1 .

Table 1. Running conditions for ICP-MS and laser ablation at University of California, Santa Barbara (UCSB), and Trinity College, Dublin (TCD). Note that for analyses performed at $\mathrm{TCD}{ }^{91} \mathrm{Zr}$ was included to monitor general signal intensity and ${ }^{88} \mathrm{Sr}$ was monitored to evaluate alteration (pristine or non-hydrothermal zircon does not contain significant levels of $\mathrm{Sr}$ ).

\begin{tabular}{ccc}
\hline Parameter & UCSB & TCD \\
\hline ICP instrument model & Nu Plasma HR MC-ICP-MS & Thermo-Scientific iCAP-Qs (quadrupole) \\
Plasma RF power (W) & 1300 & 1450 \\
Plasma gas flow (L/min) & 0.8 & 0.7 \\
Monitored masses & ${ }^{238} \mathrm{U},{ }^{232} \mathrm{Th},{ }^{208} \mathrm{~Pb},{ }^{207} \mathrm{~Pb}$, & ${ }^{238} \mathrm{U},{ }^{232} \mathrm{Th},{ }^{208} \mathrm{~Pb},{ }^{207} \mathrm{~Pb},{ }^{206} \mathrm{~Pb}$, \\
LA instrument model & ${ }^{206} \mathrm{~Pb},{ }^{204} \mathrm{~Pb} /{ }^{204} \mathrm{Hg}$ & ${ }^{204} \mathrm{~Pb} /{ }^{204} \mathrm{Hg},{ }^{200} \mathrm{Hg},{ }^{91} \mathrm{Zr},{ }^{88} \mathrm{Sr}$ \\
Laser & Photon Machines Analyte 193 & Photon Machines Analyte 193 \\
Fluence (J/cm $)$ & ATLEX-SI $193 \mathrm{~nm}$ ArF excimer & ATLEX-SI $193 \mathrm{~nm} \mathrm{ArF} \mathrm{excimer}$ \\
Repetition rate (Hz) & 3.5 & $c a .3 .3$ \\
Delay between analyses (s) & 4 & 4 \\
Ablation duration (s) & 20 & 15 \\
Carrier gas flow (L/min) & 30 & 30 \\
Spot diameter $(\boldsymbol{\mu m})$ & $0.25(\mathrm{He})$ & $0.70(\mathrm{He}), 0.006\left(\mathrm{~N}_{2}\right)$ \\
\hline
\end{tabular}

\subsection{Data Processing}

All data reduction was performed using the Iolite software package [31-34] which operates within Igor Pro [35]. Although Iolite has been available for only a few years, it has become widely adopted for its visual and interactive approach to processing very large time-integrated datasets. Once raw data have been imported from the mass spectrometer software, Iolite uses several steps to carry out data processing. These include: (1) baseline corrections; (2) defining integrations for $\mathrm{U}-\mathrm{Pb}$ primary reference materials; (3) calculating a down-hole $\mathrm{U}-\mathrm{Th}-\mathrm{Pb}$ fractionation correction; (4) defining integrations for secondary reference materials and unknowns; and (5) applying a session-wide fractionation and instrumental drift corrections. Applying a session-wide correction is a widely used approach, as it is deemed a robust way to correct for laser-induced fractionation correction $[31,33]$. Other methods of applying an inter-element fractionation include correction by linear regression, whereby the intercept gives a "true" ratio at the initial stage of ablation [36]. The VizualAge data reduction scheme [37] within Iolite was used to process data presented here. It has the capability of 
producing "live Concordia" diagrams for visualising data while selecting integration intervals during data processing. Isoplot [38] was used for plotting U-Pb data. The "TuffZirc" algorithm [39] is used to calculate an age for sample 10/225. If this algorithm can find a coherent group of at least five analyses (or $0.3 \times$ total number of analyses, whichever is larger), the age and uncertainty of the median of the coherent group is calculated. This function can tolerate up to $70 \%$ of the data being non-cogenetic (i.e., xenocrystic or suffered from Pb-loss) and produces an asymmetrical uncertainty expanded in the direction of most complexity. At best it will produce an error comparable to that of the most precise analysis used in the calculation.

\section{Results and Discussion}

\subsection{Characterizing Ablation Profiles and Down-Hole Fractionation}

Natural variation in the $U$ and Th concentration of zircon, and hence the amount of accumulated radiation damage [9], has a direct influence on zircon ablation rates [40,41]. Generally, high U zircons (e.g., up to 3000 ppm U; Plešovice zircon reference material [27]) are expected to ablate at higher rates than those with lower $U$ concentrations. Untreated and chemically abraded zircons from sample TSUPB021 were ablated during two separate analytical sessions. Measurement of ablation pit profiles from these zircons was carried out at the Centre for Microscopy and Analysis at TCD using an Omniscan MicroXan White Light Interferometer. This technique measures surface roughness and texture and is capable of rapid 3-dimensional scanning to capture data for off-line plotting and visualization. Optical interferometry has revealed differences in ablation profiles from non-treated and chemically abraded zircons (Figure 2). In general, untreated zircons ablated in a more uniform manner (Figure $2 \mathrm{a}, \mathrm{c}$ ). In terms of ablation depths, untreated zircons have pits which are $c a .25 \%$ deeper than chemically abraded counterparts (Figure 2b,d). This equates to $c a .67 \mathrm{~nm}$ and $c a .50 \mathrm{~nm}$ ablation depths per laser shot for untreated and chemically abraded zircons respectively.

The reasons for such a disparity in pit depths from TSUPB021 zircons are unclear but may be due to elimination of alpha-dose-induced crystal lattice damage in annealed zircons, a factor which contributes to a so-called "matrix effect" in LA-ICP-MS analyses [40,41]. A ca. 5\%-6\% difference in the ablation rate of several untreated and annealed zircon reference materials, including Plešovice, has previously been documented [41]. By virtue of their relatively high $\mathrm{U}$ and Th concentrations and Archean age, untreated zircons from sample TSUPB021 have a higher alpha-dose and lower density compared with most commonly used zircon reference materials. Thermal annealing of zircons results in higher densities and a corresponding shallower pit depth [41]. The considerable difference in ablation depths between pre- and post-annealed TSUPB021 zircons is presumably due to a greater disparity in crystal density when compared to similarly treated zircon reference materials [41]. At least some of the observed difference in ablation rates in untreated and chemically abraded zircons may also result from less effective laser coupling in chemically abraded zircons due to small-scale etching and creation of a 3-dimensional porous texture. This observation has important implications for the use of chemical abrasion in LA-ICP-MS analyses of zircon since down-hole fractionation increases with an increase in ablation pit depth. Assessment of down-hole fractionation of ${ }^{206} \mathrm{~Pb} /{ }^{238} \mathrm{U}$ for untreated and chemically abraded 91500 zircons reveals a distinct difference (Figure 3), with a ca. 3\% higher 
fractionation factor calculated for untreated analyses. This demonstrates chemical abrasion of zircons affects their physical response to ablation, which in turn influences laser-induced fractionation.

Figure 2. Ablation pit profiles from sample TSUPB021: (a) 3D view of untreated zircons; (b) cross-sectional view of untreated zircons; (c) 3D view of chemically abraded zircons; and (d) cross-sectional view of chemically abraded zircons.
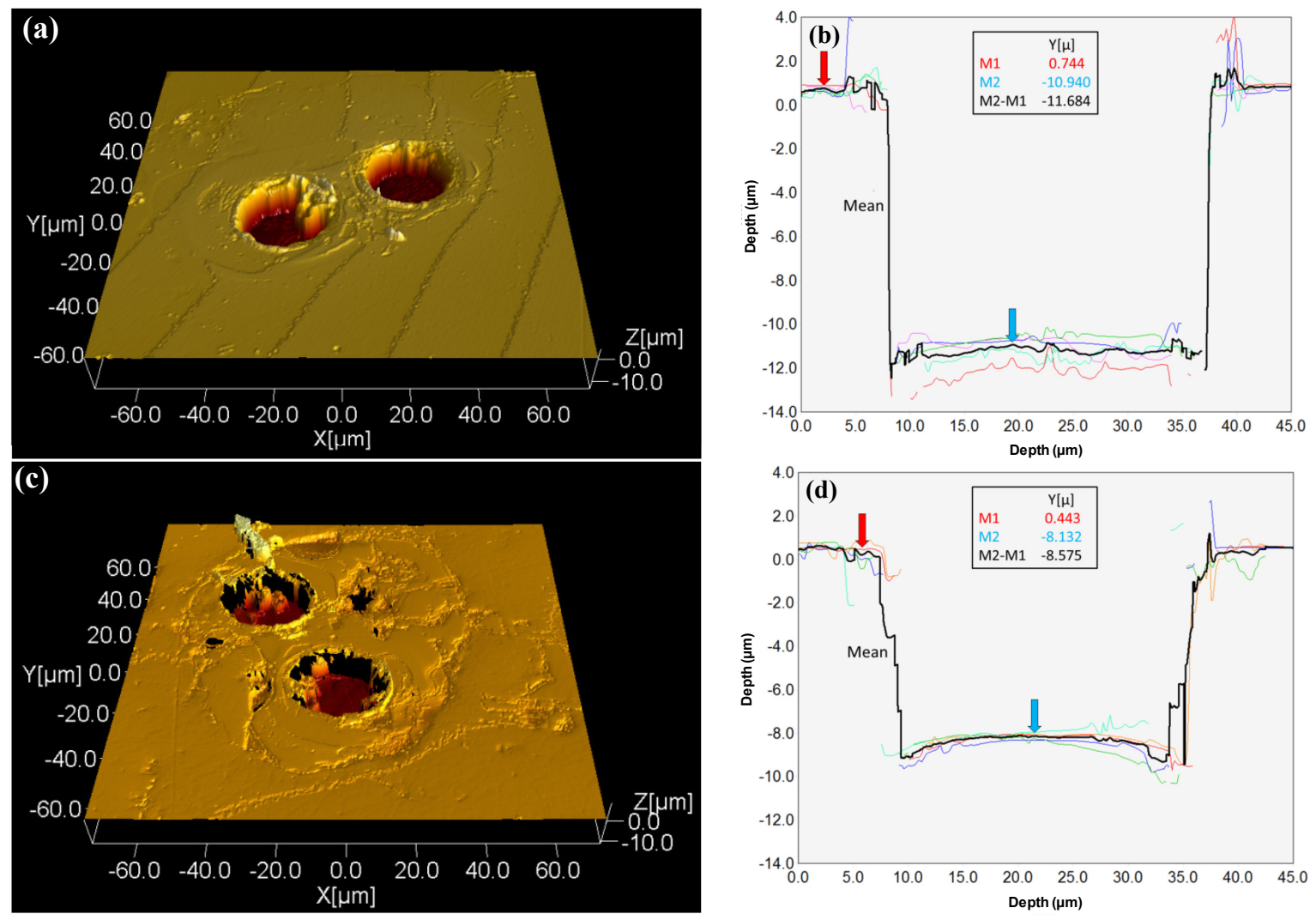

Figure 3. Comparison of time-resolved ${ }^{206} \mathrm{~Pb} /{ }^{238} \mathrm{U}$ down-hole fractionation from static ablations (30 $\mu \mathrm{m}$ spot diameter) of untreated 91500 zircon (blue lines and dashed curve) and chemically abraded 91500 zircon (pink lines and solid curve) reference materials. Pale coloured lines indicate ratios from individual analyses, whereas heavy-coloured lines represent a time-resolved mean value calculated from all analyses. Black curves are calculated as a best-fit exponential spline through mean values. There is a $c a$. 3\% difference between the two curves, taken as an average over the full duration of ablation.

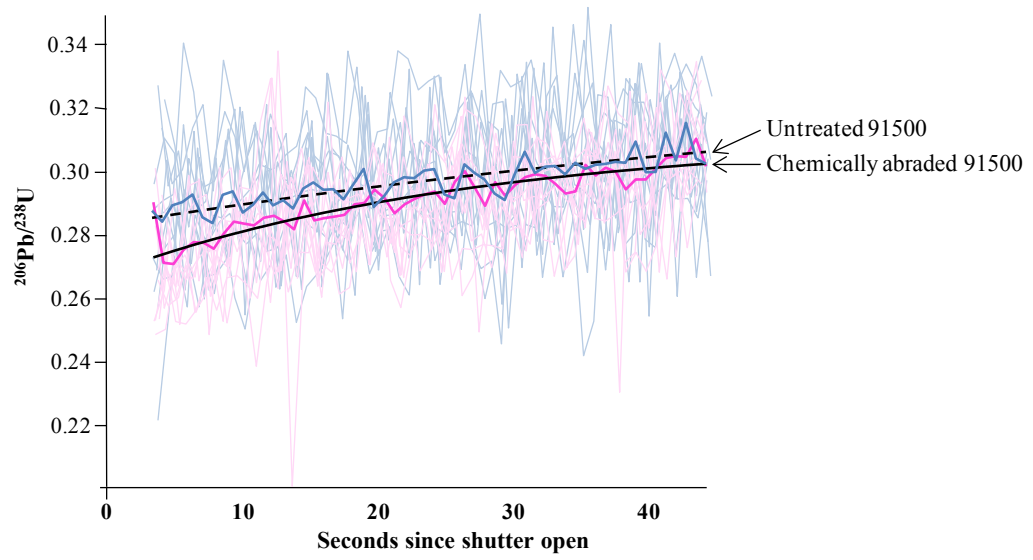




\section{2. $U-T h-P b$ Data}

$\mathrm{U}-\mathrm{Th}-\mathrm{Pb}$ data for Penglai, TSUPB021 and 10/225 are provided in the supplementary material. Errors and uncertainties are presented at a $2 \sigma$ confidence level. Chemically abraded 91500 zircon was used as a primary reference material for chemically abraded secondary reference material and chemically abraded unknowns. Plešovice zircon, which was used as a secondary reference material at both UCSB and TCD gave mean ${ }^{206} \mathrm{~Pb} /{ }^{238} \mathrm{U}$ ages of $342 \pm 23 \mathrm{Ma}$ (Mean Square of Weighted Deviation $(\mathrm{MSWD})=0.86)$ and $337.8 \pm 3 \mathrm{Ma}(\mathrm{MSWD}=5.0)$ respectively, both within error of the accepted age of $337.13 \pm 0.37 \mathrm{Ma}[27]$. All reported data are non-common $\mathrm{Pb}$ corrected.

\subsubsection{Penglai Zircon Reference Material}

Representative sub-samples of several large mm-size zircon fragments were chemically abraded and analysed by Q-ICP-MS at TCD. All 20 analyses are concordant and define a mean ${ }^{206} \mathrm{~Pb} /{ }^{238} \mathrm{U}$ age of $4.3 \pm 0.2 \mathrm{Ma}$ (Figure 4), within error of the "preferred age" of $4.4 \pm 0.1 \mathrm{Ma}$ [28].

For consistency between analytical protocols, a $30 \mu \mathrm{m}$ spot diameter was used for all analyses in this study. The resultant error of our calculated mean ${ }^{206} \mathrm{~Pb} /{ }^{238} \mathrm{U}$ age for Penglai zircons $(4.7 \% 2 \sigma$, including decay constant uncertainties) could likely be reduced with a larger spot size. The concordant nature of our data is in contrast to all published $\mathrm{U}-\mathrm{Pb}$ data for this reference material [28,29,37]. This demonstrates that chemical abrasion has preferentially and effectively removed common $\mathrm{Pb}$ from these zircons and opens the possibility of using Penglai as a primary reference material for micro-beam $\mathrm{U}-\mathrm{Pb}$ zircon geochronology, especially when analysing young $(<10 \mathrm{Ma})$ material.

Figure 4. $\mathrm{U}-\mathrm{Pb}$ data for chemically abraded Penglai zircon reference material: (a) Concordia plot; and (b) weighted mean ${ }^{206} \mathrm{~Pb} /{ }^{238} \mathrm{U}$ age. Error ellipses and box heights are $2 \sigma$. Conf:

Confidence; Wtd: weighted; Rej.: rejected; MSWD: Mean Square of Weighted Deviation.

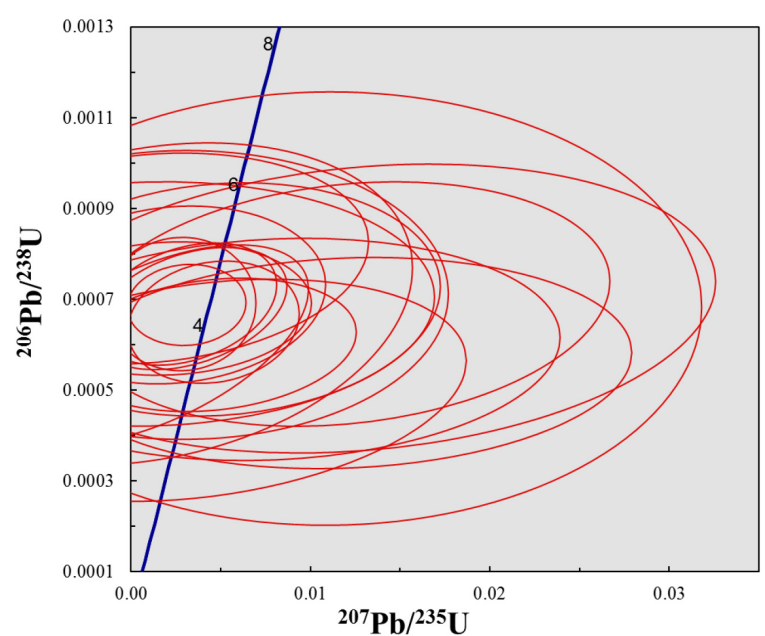

(a)

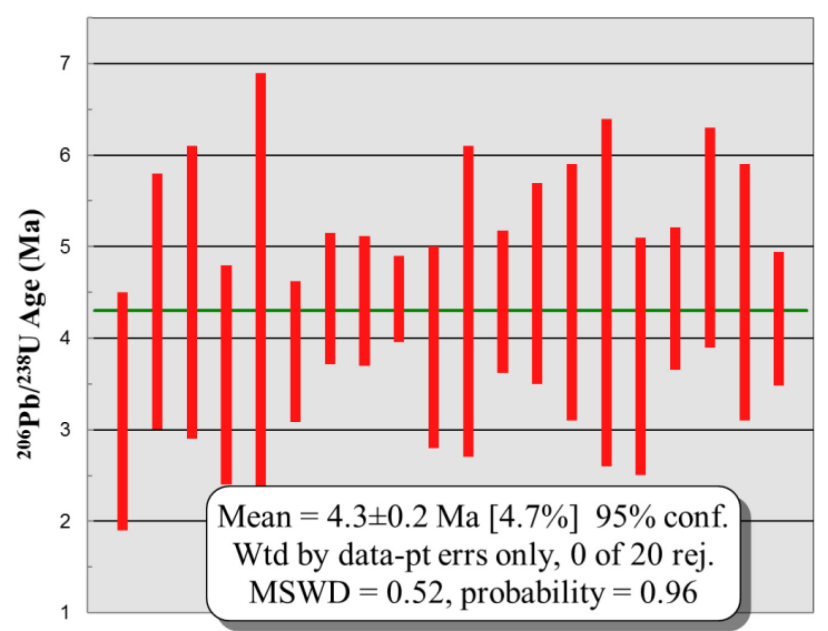

(b)

\subsubsection{Sample TSUPB021}

Both untreated $(n=77)$ and chemically abraded $(n=60)$ zircons from this sample were analysed by Q-ICP-MS at TCD. A significant proportion of untreated zircons (ca. 30\%) are discordant due to 
severe Pb-loss (Figure 5a), which is quite typical of zircons from Archean rocks. This contrasts dramatically with chemically abraded zircons from the same sample where only $3 \%$ of analyses are $>10 \%$ discordant and the remaining analyses plot close to, or overlap with, the Concordia curve (Figure 5b). Although untreated zircons from this sample display a greater range of $U$ concentration ( $c a .30$ to $7300 \mathrm{ppm}$, but mostly within $c a .30$ to $1000 \mathrm{ppm}$ ) compared to those which were chemically abraded (ca. 70 to $500 \mathrm{ppm}$ ) (Figure 6a), importantly all main age spectra present in the untreated sample are evident in the chemically abraded counterpart (Figure 6b). Minor peaks appearing in only the untreated zircons at $c a .2910$ and 3120 are likely an artefact of the relatively small number or zircons analysed.

Figure 5. U- $\mathrm{Pb}$ Concordia diagrams for sample TSUPB021: (a) Non-treated zircons; and (b) chemically abraded zircons. Data-point error ellipses are $2 \sigma$. Red ellipses: analyses $>10 \%$ discordant. Black ellipses: analyses $<10 \%$ discordant.

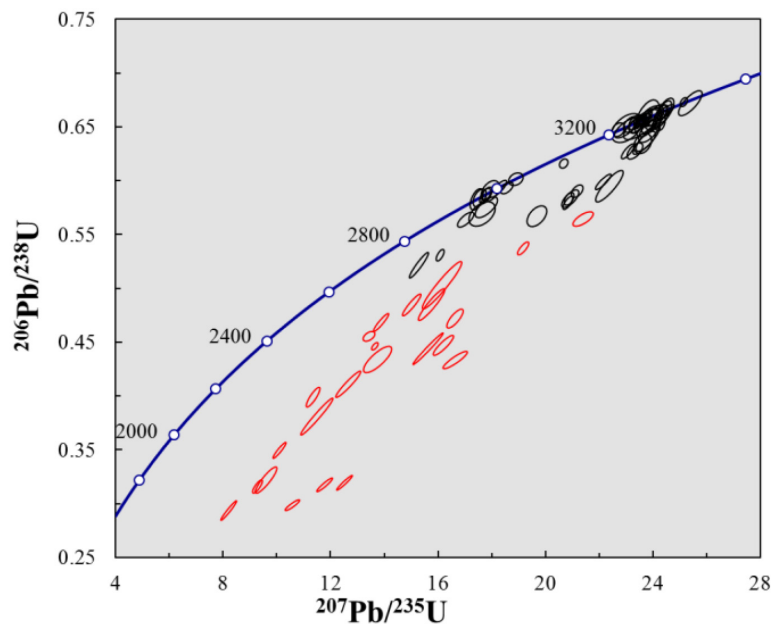

(a)

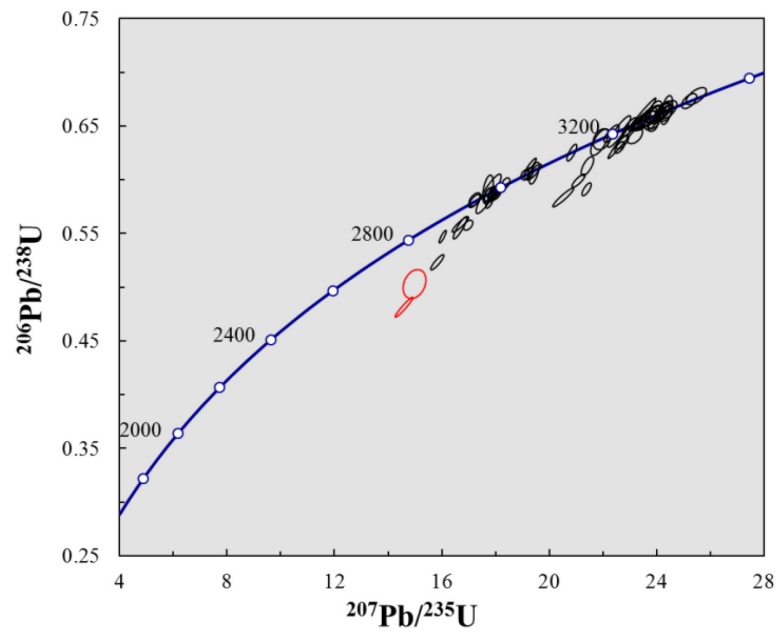

(b)

Figure 6. Chemical and age data for sample TSUPB021: (a) $\mathrm{U}$ ppm $v$ s. ${ }^{207} \mathrm{~Pb} /{ }^{206} \mathrm{~Pb}$ age (Ma), note that analyses $>c a .1100 \mathrm{ppm} U$ have not been plotted but do not define any ages not already represented in the diagram. Error ellipses are $2 \sigma$. (b) Probability-age plot for both untreated and chemically abraded zircons for analyses $<10 \%$ discordant.

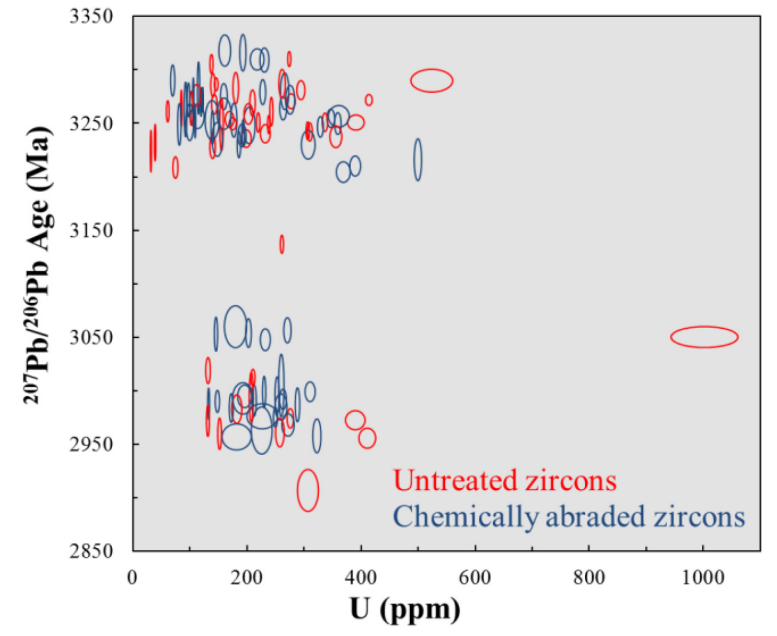

(a)

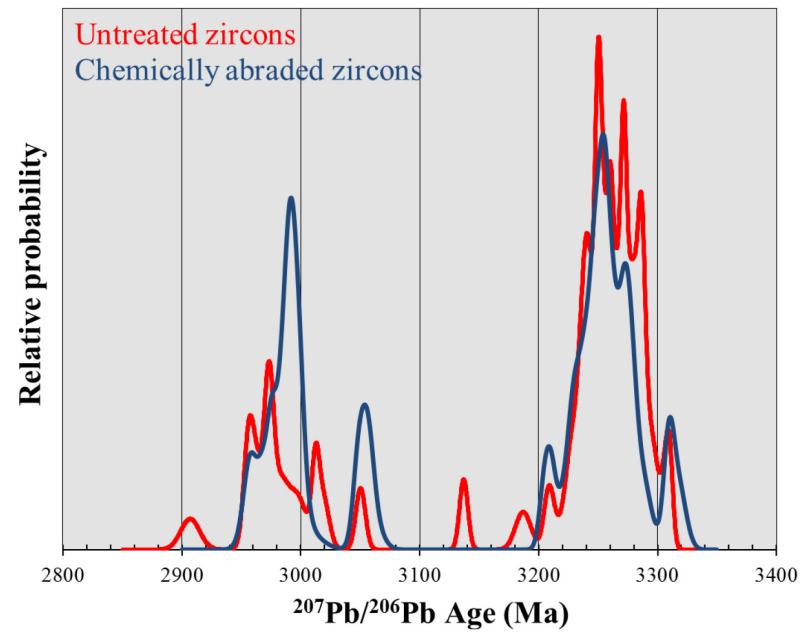

(b) 


\subsubsection{Sample $10 / 225$}

Untreated zircons from sample 10/225 were analysed at the UCSB facility. U-Pb data show a concordant cluster at $c a .480 \mathrm{Ma}$ and a large number of discordant analyses with a high degree of scatter (Figure 7a). This scatter and discordance most likely result from a combination of elevated common $\mathrm{Pb}, \mathrm{Pb}$-loss and possibly some degree of inheritance. Despite the large number of analyses $(n=109)$ and the relatively high-precision nature of the $\mathrm{U}-\mathrm{Pb}$ data, this scatter impedes a robust weighted mean age determination. Analysis of chemically abraded zircons from the same sample ( $n=33$ ) demonstrates a tight cluster of data overlapping with the Concordia curve and four discordant analyses (Figure 7b), with the latter likely reflecting "mixed ages" due to sampling of an inherited component and magmatic overgrowth. The "TuffZirc" algorithm [39] returns an age of 479.90 $\pm 1.2 \mathrm{Ma}$ for the non-treated $(n=46 / 109)$ and $479.7+5.3 /-2.2$ Ma for the chemically abraded $(n=24 / 33)$ zircon populations respectively.

Figure 7. Tera-Wasserburg plots for sample 10/225, error ellipses are $2 \sigma$ : (a) untreated zircons analysed at UCSB by LA-MC-ICP-MS; and (b) chemically abraded zircons analysed by LA-Q-ICP-MS at TCD.

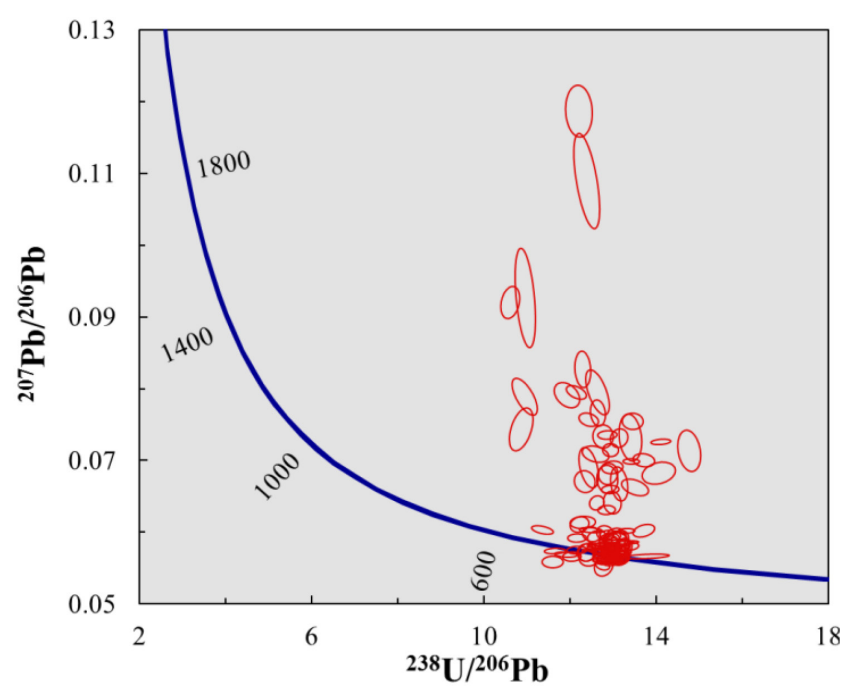

(a)

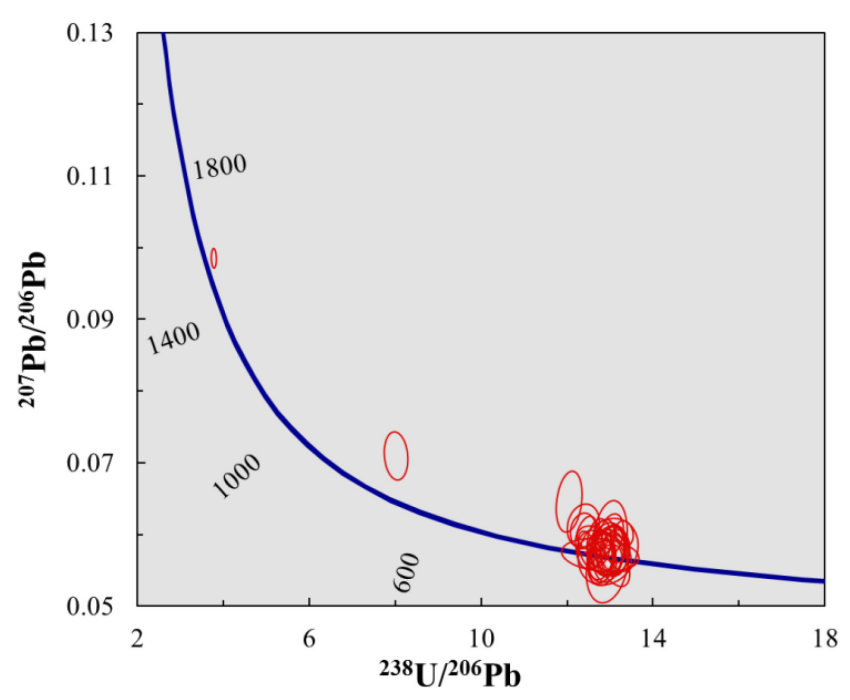

(b)

\section{Conclusions}

Chemical abrasion of zircon is an effective pre-treatment to minimize $\mathrm{Pb}$-loss and elevated common $\mathrm{Pb}$ in zircon prior to LA-ICP-MS U-Pb analysis. All our chemically abraded $\mathrm{U}-\mathrm{Pb}$ zircon data demonstrate a substantial improvement in concordance when compared with untreated zircon analyses from the same samples. Discordance is eliminated or minimized by removal of divalent $\mathrm{Pb}$ during exposure to $\mathrm{HF}$ acid at moderate temperatures $\left(180{ }^{\circ} \mathrm{C}\right)$, while leaving the remainder of the zircon crystal lattice relatively unaffected. The extent to which zircon is visibly affected by chemical abrasion, however, seems to primarily depend on $U$ concentration and the presence of physical defects, such as fractures. Zircons that display some or all of these attributes are inherently more likely to have suffered $\mathrm{Pb}$-loss, so there is an apparent correlation between the extent of $\mathrm{Pb}$-loss and the physical effects of chemical abrasion. Although this physical effect on concordant zircons appears minimal, 
comparison of down-hole fractionation of ${ }^{206} \mathrm{~Pb} /{ }^{238} \mathrm{U}$ in untreated and chemically abraded 91500 reference material reveals a $c a .3 \%$ difference, with the untreated zircons displaying a greater degree of laser-induced fractionation effects. This disparity is likely depth dependant, as ablated pits in chemically abraded high alpha-dose zircons known to have suffered $\mathrm{Pb}$-loss are up to $25 \%$ shallower than ablation pits in untreated zircons from the same sample. Although this may be an extreme example, it illustrates that primary reference materials should be chemically abraded when analysing chemically abraded unknowns and secondary reference materials. It does not, however, eliminate the possibility that reference materials and unknowns will respond differently to the treatment, thereby resulting in differing down-hole fractionation of $\mathrm{U}-\mathrm{Pb}$ and $\mathrm{Th}-\mathrm{Pb}$ isotopes. Accurate measurement and comparison of ablation depths may help to minimize a mismatch between reference materials and sample down-hole fractionation corrections.

Analysis of zircons from an Archean sample (TSUPB021) demonstrates preferential dissolution of zircon at $\mathrm{U}$ concentrations greater than $c a .1100 \mathrm{ppm}$, the majority of which are severely discordant as measured in untreated counterparts. In this particular case the main age spectra between untreated and chemically abraded zircons are identical, although it would in theory be possible to bias a sample by preferential dissolution of high-U zircons with a distinct age signature. Although higher $\mathrm{U}$ zircons (up to $1400 \mathrm{ppm}$ ) have been reported to have survived intact following chemical abrasion [22], these instances have been from considerably younger zircons. The chemical abrasion technique should therefore be used with caution when dealing with Archean zircons with elevated U concentrations.

In summary, although initially developed for TIMS U-Pb geochronology, chemical abrasion can easily and routinely be applied as a pre-treatment protocol to improve concordance for the majority of samples for LA-ICP-MS U-Pb geochronology.

\section{Acknowledgments}

Thanks to Tony Simonetti for his suggestion to write this research paper and to two anonymous reviewers for their constructive comments. Both Andrew Kylander-Clark and Cora McKenna are thanked for their assistance with mass spectrometry at UCSB and TCD respectively.

\section{Author Contributions}

Quentin G. Crowley developed the experiment design, carried out the majority of sample analyses and drafted the paper. All co-authors contributed to the writing of this paper. Kyle Heron collected sample TSUPB021, carried out rock crushing and mineral separation of samples TSUPB021 and 10/225, analyzed sample TSUPB021, performed CL imaging and measurement of pit depth profiles. Nancy Riggs carried out analysis of the non-treated sample 10/225 at UCSB. Balz Kamber supplied Penglai zircon reference material. David Chew supplied 91500 zircon reference material. Brian McConnell assisted with collection of sample 10/225. Keith Benn assisted with collection of sample TSUPB021.

\section{Conflicts of Interest}

The authors declare no conflict of interest. 


\section{References}

1. Kulp, J.L.; Bate, G.L.; Broecker, W.S. Present status of the lead method of age determination. Am. J. Sci. 1954, 252, 345-365.

2. Tilton, G.R.; Patterson, C.; Brown, H.; Inghram, M.; Hayden, R.; Hess, D.; Larsen, E. Isotopic composition and distribution of lead, uranium, and thorium in a Precambrian granite. Geol. Soc. Am. Bull. 1955, 66, 1131-1148.

3. Wetherill, G.W. Discordant uranium-lead ages: 2. Disordant ages resulting from diffusion of lead and uranium. J. Geophys. Res. 1963, 68, 2957-2965.

4. Nier, A.O. Variations in the relative abundances of the isotopes of common lead from various sources. J. Am. Chem. Soc. 1938, 60, 1571-1576.

5. Finch, R.J.; Hanchar, J.M. Structure and chemistry of zircon and zircon-group minerals. Rev. Mineral. Geochem. 2003, 53, 1-25.

6. Kogawa, M.; Watson, E.B.; Ewing, R.C.; Utsunomiya, S. Lead in zircon at the atomic scale. Am. Mineral. 2012, 97, 1094-1102.

7. Cherniak, D.; Watson, E. Pb diffusion in zircon. Chem. Geol. 2001, 172, 5-24.

8. Lee, J.K.; Williams, I.S.; Ellis, D.J. Pb, U and Th diffusion in natural zircon. Nature 1997, 390, $159-162$.

9. Nasdala, L.; Hanchar, J.M.; Kronz, A.; Whitehouse, M.J. Long-term stability of alpha particle damage in natural zircon. Chem. Geol. 2005, 220, 83-103.

10. Tanaka, K.; Takahashi, Y.; Horie, K.; Shimizu, H.; Murakami, T. Determination of the oxidation state of radiogenic $\mathrm{Pb}$ in natural zircon using $\mathrm{X}$-ray absorption near-edge structure. Phys. Chem. Miner. 2010, 37, 249-254.

11. Xu, X.-S.; Zhang, M.; Zhu, K.-Y.; Chen, X.-M.; He, Z.-Y. Reverse age zonation of zircon formed by metamictisation and hydrothermal fluid leaching. Lithos 2012, 150, 256-267.

12. Kramers, J.; Frei, R.; Newville, M.; Kober, B.; Villa, I. On the valency state of radiogenic lead in zircon and its consequences. Chem. Geol. 2009, 261, 4-11.

13. MacDonald, J.M.; Wheeler, J.; Harley, S.L.; Mariani, E.; Goodenough, K.M.; Crowley, Q.; Tatham, D. Lattice distortion in a zircon population and its effects on trace element mobility and U-Th-Pb isotope systematics: Examples from the Lewisian Gneiss Complex, northwest Scotland. Contrib. Mineral. Petrol. 2013, 166, 21-41.

14. Krogh, T. Improved accuracy of $\mathrm{U}-\mathrm{Pb}$ zircon ages by the creation of more concordant systems using an air abrasion technique. Geochim. Cosmochim. Acta 1982, 46, 637-649.

15. Mattinson, J.M. Zircon U-Pb chemical abrasion ("CA-TIMS") method: Combined annealing and multi-step partial dissolution analysis for improved precision and accuracy of zircon ages. Chem. Geol. 2005, 220, 47-66.

16. Krogh, T.; Davis, G. Alteration in zircons with discordant U-Pb ages. Carnegie Inst. Wash. Yearb. 1974, 73, 560-567.

17. Krogh, T.; Davis, G. Alteration in zircons and differential dissolution of altered and metamict zircon. Carnegie Inst. Wash. Yearb. 1975, 74, 619-623.

18. Mattinson, J.M. A study of complex discordance in zircons using step-wise dissolution techniques. Contrib. Mineral. Petrol. 1994, 116, 117-129. 
19. McClelland, W.C.; Mattinson, J.M. Resolving high precision U-Pb ages from Tertiary plutons with complex zircon systematics. Geochim. Cosmochim. Acta 1996, 60, 3955-3965.

20. Todt, W.A.; Büsch, W. U-Pb investigations on zircons from pre-Variscan gneisses-I. A study from the Schwarzwald, West Germany. Geochim. Cosmochim. Acta 1981, 45, 1789-1801.

21. Crowley, Q.; Key, R.; Noble, S. High-precision U-Pb dating of complex zircon from the Lewisian Gneiss Complex of Scotland using an incremental CA-ID-TIMS approach. Gondwana Res. 2014, doi:10.1016/j.gr.2014.04.001.

22. Kryza, R.; Crowley, Q.G.; Larionov, A.; Pin, C.; Oberc-Dziedzic, T.; Mochnacka, K. Chemical abrasion applied to SHRIMP zircon geochronology: An example from the Variscan Karkonosze Granite (Sudetes, SW Poland). Gondwana Res. 2012, 21, 757-767.

23. McConnell, B.; Riggs, N.; Crowley, Q.G. Detrital zircon provenance and Ordovician terrane amalgamation, western Ireland. J. Geol. Soc. 2009, 166, 473-484.

24. Riggs, N.R.; Barth, A.P.; González-León, C.M.; Jacobson, C.E.; Wooden, J.L.; Howell, E.R.; Walker, J.D. Provenance of Upper Triassic Strata in Southwestern North America as Suggested by Isotopic Analysis and Chemistry of Zircon Crystals. In Mineralogical and Geochemical Approaches to Provenance; Rasbury, E.T., Hemming, S.R., Riggs, N.R., Eds.; Special Paper Volume 487; Geological Society of America: Boulder, CO, UDA, 2012; pp. 13-36.

25. Riggs, N.; Reynolds, S.; Lindner, P.; Howell, E.; Barth, A.; Parker, W.; Walker, J. The early Mesozoic cordilleran arc and late Triassic paleotopography: The detrital record in Upper Triassic sedimentary successions on and off the Colorado Plateau. Geosphere 2013, 9, 602-613.

26. Wiedenbeck, M.; Alle, P.; Corfu, F.; Griffin, W.; Meier, M.; Oberli, F.; Quadt, A.V.; Roddick, J.; Spiegel, W. Three natural zircon standards for $\mathrm{U}-\mathrm{Th}-\mathrm{Pb}, \mathrm{Lu}-\mathrm{Hf}$, trace element and REE analyses. Geostand. Newsl. 1995, 19, 1-23.

27. Sláma, J.; Košler, J.; Condon, D.J.; Crowley, J.L.; Gerdes, A.; Hanchar, J.M.; Horstwood, M.S.; Morris, G.A.; Nasdala, L.; Norberg, N. Plešovice zircon-A new natural reference material for $\mathrm{U}-\mathrm{Pb}$ and $\mathrm{Hf}$ isotopic microanalysis. Chem. Geol. 2008, 249, 1-35.

28. Li, X.H.; Long, W.G.; Li, Q.L.; Liu, Y.; Zheng, Y.F.; Yang, Y.H.; Chamberlain, K.R.; Wan, D.F.; Guo, C.H.; Wang, X.C. Penglai zircon megacrysts: A potential new working reference material for microbeam determination of $\mathrm{Hf}-\mathrm{O}$ isotopes and $\mathrm{U}-\mathrm{Pb}$ age. Geostand. Geoanal. Res. 2010, 34, 117-134.

29. Chew, D.; Petrus, J.; Kamber, B. U-Pb LA-ICPMS dating using accessory mineral standards with variable common Pb. Chem. Geol. 2014, 363, 185-199.

30. Kylander-Clark, A.R.; Hacker, B.R.; Cottle, J.M. Laser-ablation split-stream ICP petrochronology. Chem. Geol. 2013, 345, 99-112.

31. Hellstrom, J.; Paton, C.; Woodhead, J.; Hergt, J. Iolite: Software for Spatially Resolved LA-(QUAD and MC) ICPMS Analysis. In Laser Ablation ICP-MS in the Earth Sciences: Current Practices and Outstanding Issues; Sylvester, P., Ed.; Short Course 40; Mineralogical Association of Canada: Quebec City, QC, Canada, 2008; pp. 343-348.

32. Woodhead, J.; Hellstrom, J.; Paton, C.; Hergt, J.; Greig, A.; Maas, R. A Guide to Depth Profiling and Imaging Applications of LA-ICP-MS. In Laser Ablation ICP-MS in the Earth Sciences: Current Practices and Outstanding Issues; Sylvester, P., Ed.; Short Course 40; Mineralogical Association of Canada: Quebec City, QC, Canada, 2008; pp. 135-145. 
33. Paton, C.; Hellstrom, J.; Paul, B.; Woodhead, J.; Hergt, J. Iolite: Freeware for the visualisation and processing of mass spectrometric data. J. Anal. At. Spectrom. 2011, 26, 2508-2518.

34. The Iolite Project. Available online: http://www.iolite.org.au (accessed on 26 May 2014).

35. WaveMetrics. Available online: http://www.wavemetrics.com (accessed on 26 May 2014).

36. Janoušek, V.; Gerdes, A.; Vrána, S.; Finger, F.; Erban, V.; Friedl, G.; Braithwaite, C.J.R. Low-pressure granulites of the Lišov Massif, southern Bohemia: Viséan metamorphism of late Devonian plutonic arc rocks. J. Petrol. 2006, 47, 705-744.

37. Petrus, J.A.; Kamber, B.S. VizualAge: A novel approach to laser ablation ICP-MS U-Pb geochronology data reduction. Geostand. Geoanal. Res. 2012, 36, 247-270.

38. Isoplot Version 4.1. Available online: http://www.bgc.org/isoplot_etc/isoplot.html (accessed on 29 May 2014).

39. Ludwig, K.; Mundil, R. Extracting reliable U-Pb ages and errors from complex populations of zircons from Phanerozoic tuffs. Geochim. Cosmochim. Acta 2002, 66, A463.

40. Allen, C.M.; Campbell, I.H. Identification and elimination of a matrix-induced systematic error in LA-ICP-MS ${ }^{206} \mathrm{~Pb} /{ }^{238} \mathrm{U}$ dating of zircon. Chem. Geol. 2012, 332, 157-165.

41. Marillo-Sialer, E.; Woodhead, J.; Hergt, J.; Greig, A.; Guillong, M.; Gleadow, A.; Evans, N.; Paton, C. The zircon "matrix effect": Evidence for an ablation rate control on the accuracy of U-Pb age determinations by LA-ICP-MS. J. Anal. At. Spectrom. 2014, 29, 981-989.

(C) 2014 by the authors; licensee MDPI, Basel, Switzerland. This article is an open access article distributed under the terms and conditions of the Creative Commons Attribution license (http://creativecommons.org/licenses/by/3.0/). 